\title{
Case Report: Challenges of Rehabilitation Interventions in Beaulieu-boycott-innes Syndrome: A Case Report
}

\author{
Masoud Gharib $^{1^{*}}$ (D), Roshanak Vameghi² (i), Mohsen Fallahi ${ }^{3}$ (iD)
}

1. Orthopedic Research Center, Mazandaran University of Medical Sciences, Sari, Iran.

2. Pediatric Neurorehabilitation Research Center, University of Social Welfare and Rehabilitation Sciences, Tehran, Iran.

3. Department of Rehabilitation, Faculty of Paramedicine, Mazandaran University of Medical Sciences, Sari, Iran.

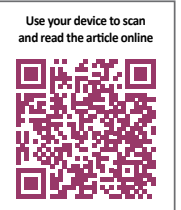

ditation: Gharib M, Vameghi R, Fallahi M. Challenges of Rehabilitation Interventions in Beaulieu-boycott-innes Syndrome. Iranian Rehabilitation Journal. 2020; 18(4):503-506. http://dx.doi.org/10.32598/irj.18.4.100.7

dof $\mathrm{http://dx.doi.org/10.32598/irj.18.4.100.7}$

Article info:

Received: 11 May 2020

Accepted: 01 Aug 2020

Available Online: 01 Dec 2020

\section{Keywords:}

Beaulieu-Boycott-Innes Syndrome (BBIS),

Developmental delay,

Rehabilitation

\section{ABSTRACT}

Beaulieu-Boycott-Innes syndrome (BBIS), an autosomal recessive disorder, is characterized by dysmorphic facial features and developmental delay. In this case study, we used the age and stages questionnaire 2 (ASQ-2) to assess the developmental status of an Iranian 20-month-old girl displaying a complex BBIS phenotype. Rehabilitation interventions were designed and performed focusing on neurodevelopmental delay. Because she had a severe developmental delay and her scores in all five domains of ASQ-2 were below the cut-off points available for Iranian children, the effectiveness of rehabilitation interventions was slower than expected. It seems that early rehabilitation and close follow-up should be considered for these children. We can assume that early and properly sensory-motor and cognitive interventions in these children may lead to growth development and prevent secondary complications.

\section{* Corresponding Author:}




\section{Highlights}

- Beaulieu-Boycott-Innes syndrome (BBIS) is a rare disorder reported for the first time in the Iranian population.

- Developmental delay exists in all domains (gross motor, fine motor, communication, and cognition) in BBIS.

- Rehabilitation interventions may help the facilitation of development in BBIS.

\section{Plain Language Summary}

Beaulieu-Boycott-Innes syndrome (BBIS), a genetic disorder, is characterized by dysmorphic facial features and developmental delay,Therefore, rehabilitation services are necessary. Occupational therapy is usually part of the rehabilitation package of interventions for persons with disabilities. The primary purpose of occupational therapy is to promote and achieve functional independence. In this case study, we assess developmental status with the age and stages questionnaire 2 (ASQ-2) of an Iranian 20-month-old girl. the effectiveness of rehabilitation interventions was slower than expected. It seems that early rehabilitation and close follow-up should be considered for these children. We can assume that early and properly sensory-motor and cognitive interventions in these children may lead to growth development and prevent secondary complications.

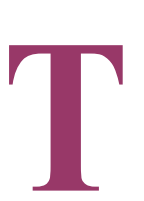

\section{Introduction}

he THO Complex 6 gene (THOC6) encodes part of the THO/TREX (transcription/export) complex, which is responsible for mRNA replication, processing, and nuclear export of spliced mRNA [1, 2]. In 2013, Boycott et al. found an association between a homozygous mutation in THOC6 and a particular type of autosomal recessive Intellectual Disability (ID) in a Hutterite family and reported it for the first time. They called it the Beaulieu-Boycott-Innes syndrome (BBIS) [3]. In 2018, Accogli et al. reported new CNS malformations and skeletal anomalies in BBIS [4].

The THOC6 variant, $\mathrm{c} 220+1 \mathrm{G}>\mathrm{A}$, has been described as a pathogenic variant according to the American College of Medical Genetics (ACMG) database. Pathogenic variants in this gene are associated with Beaulieu-Boycott-Innes Syndrome (BBIS), which is due to homozygous or compound heterozygous mutation in the THOC6 gene on chromosome 16p13 (OMIM613680).

Developmental delay and dysmorphic facial features are the main characteristics of BBIS. However, other developmental anomalies might be seen with this autosomal recessive disorder, such as corpus callosum dysgenesis, submucous cleft palate, cryptorchidism in males, and cardiac and renal defects.

Mild to moderate ID, mild microcephaly to borderlinenormal head circumference, and anteriorly displaced anus are among clinical manifestations of recessive mutations in THOC. Moreover, the disorder has also been seen with various craniofacial dysmorphisms such as short up-slanting palpebral fissure and malocclusion and a tall forehead. It should be considered that most of these characteristics are not specific. So, its diagnosis is challenging for genetic specialists [3].

Occupational therapy is usually part of the rehabilitation package of interventions for persons with disabilities. The primary purpose of occupational therapy is to promote and achieve functional independence.

There have been a few case reports on BBIS among the Italian [3], Hutterite [4] and Saudi Arabic [5], French, and our communities, and there has been one report or research on this syndrome in the Iranian population [6] We did not find any recommendations for rehabilitation interventions related to this disorder in the current literature. So here we report an Iranian 20-month-old girl displaying a complex BBIS phenotype with a new body and face dysmorphia owing to homozygous variants in the THOC6 gene for whom we started early intervention based on facilitation of motor and cognitive development

\section{Case Presentation}

A 20-month-old girl with delayed developmental millstones was referred to our occupational therapy clinic. She was on L-carnitine because of positive findings in her EEG. She was the first-born child in her family. Her parents were healthy, and she was born full term. She 
had a cardiac septal defect for which she had undergone. She had a tall forehead and a high anterior hairline in her face. Also, she had microcephaly diagnosed by a pediatrician. She was referred for genetic studies because of her dysmorphic features, which approved a pathogenic variant of the THOC6 gene, with an autosomal recessive inheritance. A such, she received a diagnosis of the Beaulieu-Boycott-Innes Syndrome (BBIS).

We used the Age and Stages Questionnaire 2 (ASQ-2) (questionnaire for 20-months old infants) to assess the child's developmental status. ASQ includes five developmental domains: communication, gross motor, fine motor, problem-solving, and personal-social. According to ASQ-2, she had a severe developmental delay, and her scores in all five domains were below the cut-off points available for Iranian children [7].

In terms of gross motor development, the 20-monthold child could neither sit nor stand independently, and she did not creep or crawl. When her parents helped her by holding her hands, she could not walk. She was only able to roll from supine to prone position.

In terms of communication development, she could not say any words, even /mama/ or /baba/ imitatively. She could not point at the pictures that the observer asked her to point.

In the problem-solving domain, she could not scribble either with a pencil or crayons. She did not imitate drawing lines. She could not imitate her parents in putting two cubes or Legos together in a specific pattern. When objects were out of her reach, she could not use problemsolving skills to reach them. She could not imitate her mother in blinking.

In terms of self-care and social development (personalsocial domain), she did not use a spoon for eating. She could not use a glass or cup for drinking. She does not have a functional imitation. The child also had a cardiac septal defect. However, unlike the patient reported by Gupta et al. with this syndrome [8], she did not have a renal defect.

\section{Discussion}

\section{Rehabilitation plan}

The occupational therapy interventions were planned and provided for the child focused mainly on gross motor activities such as throwing a ball and facilitating motor skills such as crawling and creeping or keeping bal- ance on standing posture. For the facilitation of creeping and crawling, we used a wedge as a facilitator surface. Because of lack of equilibrium and protective reaction, we facilitated those reactions by using a sitting position with support on a tilt board. Because of the hypotonia detected in the child's upper and lower extremities, we included weight bearing, heavy joint compression, tapping, quick stretching, positioning, and handling in the rehabilitation plan. Swiss ball gentle rocking and shaking, as well as swinging, were also included to increase proprioceptive and vestibular sensations. Since playing and interacting in peer groups can generally enhance communication development, as well as hand function, problem-solving skills, and cognitive ability in the child, we suggested that she be sent to a child day-care center or nursery for a few hours each day. Other forms of group activities with friends, siblings, or parents were recommended for the same purpose.

Since the diagnosis, the child has attended 3 occupational therapy sessions every week, but her progress was slow. This outcome may be because we are in the early stages of rehabilitation.

\section{Conclusion}

In our report, we demonstrated that Beaulieu-BoycottInnes syndrome had a significant clinical feature, i.e. severe delay in all developmental domains. Other reports have not demonstrated communication and social development defects.

Since most of these features are relatively non-specific and are likely to be seen in other genetic disorders, to assess the relevance of the THOC6 variants, significant weight was more important than craniofacial features, which were previously considered in recognizing this syndrome.

To our knowledge, unfortunately, there has been no report on rehabilitation protocols or outcomes of this syndrome in the literature. Therefore, the focus of rehabilitation is more on facilitating cognitive-motor development according to the child's age. We suggest that more research be conducted to help therapists decide on better and more effective interventions. However, since the outcome of early detection and early intervention in different developmental disorders has always been reassuring, we can speculate that early sensory-motor and cognitive interventions in these children may result in some developmental improvement and prevent secondary complications. 


\section{Ethical Considerations}

Compliance with ethical guidelines

All ethical principles were considered in this article.

Funding

This research did not receive any grant from funding agencies in the public, commercial, or non-profit sectors.

Authors' contributions

All authors equally contributed to preparing this article.

\section{Conflict of interest}

The authors declared no conflict of interest.

\section{References}

[1] Hur JK, Luo Y, Moon S, Ninova M, Marinov GK, Chung YD, et al. Splicing-independent loading of TREX on nascent RNA is required for efficient expression of dual-strand piRNA clusters in Drosophila. Genes \& Development. 2016; 30(7):840-55. [DOI:10.1101/gad.276030.115] [PMID] [PMCID]

[2] Masuda S, Das R, Cheng H, Hurt E, Dorman N, Reed R. Recruitment of the human TREX complex to mRNA during splicing. Genes \& Development. 2005; 19(13):1512-7. [DOI:10.1101/gad.1302205] [PMID] [PMCID]

[3] Beaulieu CL, Huang L, Innes AM, Akimenko MA, Puffenberger EG, Schwartz C, et al. Intellectual disability associated with a homozygous missense mutation in THOC6. Orphanet Journal of Rare Diseases. 2013; 8(1):62. [DOI:10.1186/17501172-8-62] [PMID] [PMCID]

[4] Accogli A, Scala M, Calcagno A, Castello R, Torella A, Musacchia F, et al. Novel CNS malformations and skeletal anomalies in a patient with Beaulieu-boycott-Innes syndrome. American Journal of Medical Genetics Part A. 2018; 176(12):2835-40. [DOI:10.1002/ajmg.a.40534] [PMID]

[5] Anazi S, Alshammari M, Moneis D, Abouelhoda M, Ibrahim N, Alkuraya FS. Confirming the candidacy of THOC6 in the etiology of intellectual disability. American Journal of Medical Genetics Part A. 2016; 170(5):1367-9. [DOI:10.1002/ ajmg.a.37549] [PMID]

[6] Amos JS, Huang L, Thevenon J, Kariminedjad A, Beaulieu C, Masurel-Paulet A, et al. Autosomal recessive mutations in THOC6 cause intellectual disability: syndrome delineation requiring forward and reverse phenotyping. Clinical Genetics. 2017; 91(1):92-9. [DOI:10.1111/cge.12793] [PMID]

[7] Vameghi R, Sajedi F, Mojembari AK, Habiollahi A, Lornezhad HR, Delavar B. Cross-cultural adaptation, validation and standardization of Ages and Stages Questionnaire (ASQ) in Iranian children. Iranian Journal of Public Health. 2013 42(5):522-28. [PMCID] [PMID]
[8] Gupta N, Yadav S, Gurramkonda VB, Ramprasad V, Thenral S, Kabra M. First report of THOC6 related intellectual disability (Beaulieu Boycott Innes syndrome) in two siblings from India. European Journal of Medical Genetics. 2020; 63(3):103742. [DOI:10.1016/j.ejmg.2019.103742] [PMID] 